\title{
Literal Digital
}

ALFIE KOETTER

University of Southern California
EMMETT ZEIFMAN

Columbia University

Figure 1. Museum 001, Medium Office.

In the spirit of opening the black box, to see what, if anything is inside, we thought we'd talk about how we work, particularly how we work with computers, and in so doing, to try to reflect on the ways in which computation today structures the field and the work we produce.

For us, as for the rest of the world, architects and otherwise, there is only "the digital"-the use of computational tools is ubiquitous, and no longer in and of itself represents a genre, niche or avant-garde approach. ${ }^{1}$ With respect to the world, we are on the Gen-X cusp of millennial, and so we remember a childhood without the internet, and an adolescence without smartphones. But we are young enough that computers did not in any way consciously transform or upend our lives. They simply happened, slowly at first, and then all at once, without anyone our age missing a beat (or losing a job). Some people took them more seriously than others, became "computer" people, but we all took to them "naturally." And as far as our architectural education and training goes, we are "digital natives." ${ }^{2}$ Our use of digital software to produce architecture has never been exceptional or even optional; it has always been a given and a requirement. Though we are (just barely) old enough to have been taught to draw by hand in anachronistic introductory courses, we entered an already "digital" discipline, in which the standard suite of tools that we were introduced to and expected to use as students remain those which we use today (namely, AutoCAD, Rhino, Illustrator, Photoshop). More specifically, we entered the discipline at a moment when Rhino became firmly entrenched as the primary modeling software, missing the heyday of Maya and formZ before it, and sidestepping the emergence of 


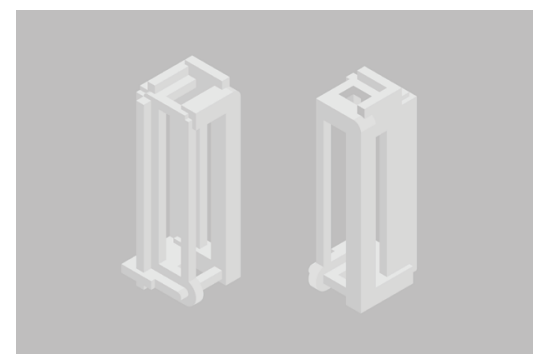

Figure 2. Urbanism 002, Medium Office.

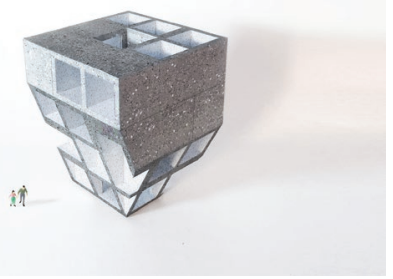

Figure 5. Housing 001, Medium Office.

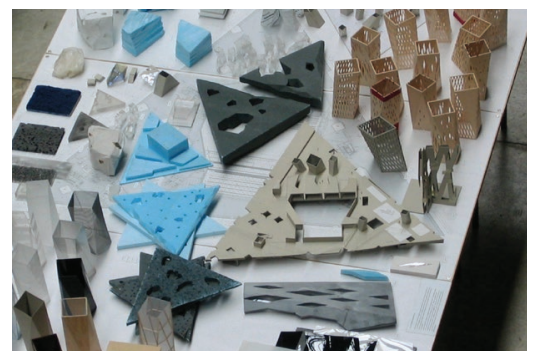

Figure 8. Models, Herzog de Meuron.

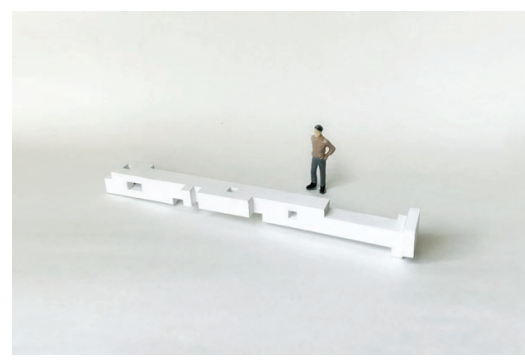

Figure 3. Study 014, Medium Office.

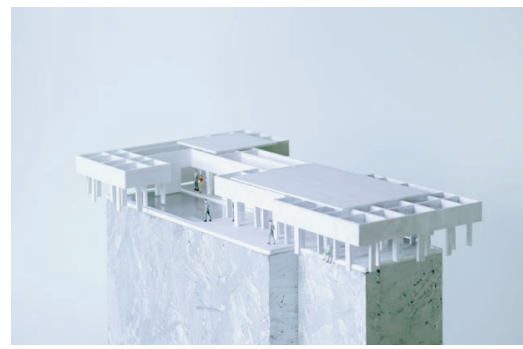

Figure 6. Pavillion 004, Medium Office.

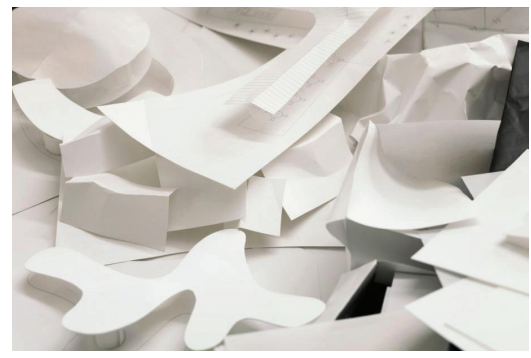

Figure 9. Models, SANAA.

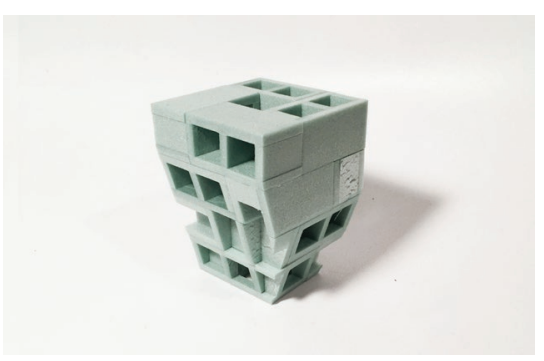

Figure 4. Housing 001, Medium Office.

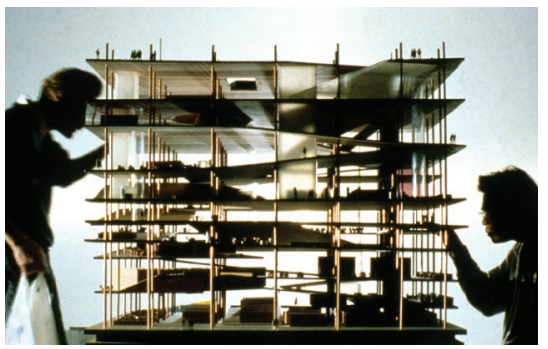

Figure 7. Jussieu Model, OMA.

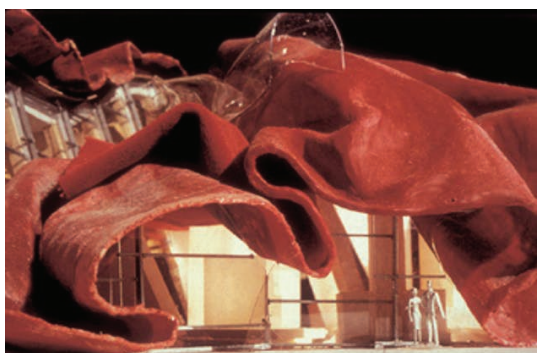

Figure 10. Lews Residence Model, Frank Gehry.
Grasshopper and Revit (the latter because we left corporate office jobs before we could be properly trained to participate in the architectural workforce of the future). We are perhaps particularly characteristic of the present state of the "digital," in the sense that our skill set represents the minimum required to engage in the discipline and in small-scale professional work, and no more-we occupy a digital plateau. We're not early adopters or late bloomers or reactionaries or revolutionaries. As the name of our practice suggests, we're medium, somewhere near the average in both our digital skills and digital ambitions, which are not measured in computational power, complex geometries or patterns, ever-new plugins or scripts, and other measures of digital expertise or exceptionalism.

\section{TOOLS}

Our immersion in this ubiquitously digital field does not mean that we are unaware of the ways in which we use the digital tools at our disposal. But for us a tool is a tool. A drill is good for making holes; Rhino is good for extruding profiles. A table saw is good for cutting straight lines in sheet materials; Photoshop is good for pixelating images. A hammer is good for breaking car windows; Illustrator is good for giving lines thickness. Like most architects who are not in offices using Revit, our everyday work occurs through software that is not specifically architectural. So we use those aspects of the software that have risen to the surface within the field, those that are partiwcularly good at doing things that architects tend to want to do: turn lines into surfaces and vice versa; figure out what material something should be; make images that look good on websites and social media platforms; also make drawing sets that contractors can read. Someone else might try to jury-rig a drill into some sort of spindle sander, but we wouldn't. We don't feel the need to pervert our tools, or develop a continually broader expertise in the way we use any of our tools, learning new commands and adding new plug-ins so as discover new geometries or ways of processing images; we're comfortable with simple proficiency in the basics, a common standard of knowledge that perhaps 
increases the accessibility of our work, which we do not strive to make self-consciously different, and which, in its fundamental geometric and material characteristics, is a lot like a lot of other work.

Whenever possible, we defer to the tools that we use when making a design decision. Because we use a limited set of tools in limited ways, we have produced a relatively consistent body of work which contains trace evidence of the software through which it was developed: forms can be understood in terms of Rhino commands like "extrude" or "booleanintersection" (figure 1); their corners in terms of Illustrator's "cap" and "corner" options (figure 2); if anything is pixelated, that's a product of Photoshop's "image setting" (figure 3 ).

If our work has a lot of straight lines, it's also because we tend to make models on a foam cutter (figure 4), our only "power" tool (except a printer) in our decidedly simple "maker" space or "fablab" (a desk with a cutting mat). Like a table saw, the foam cutter is best at cutting straight lines, and like modeling cleanly in Rhino, modeling with foam works best through the accumulation of solid objects. Its output laminated with printed paper ("texture-mapped") (figure 5), the foam cutter, or its even lower-tech cousin, foamcore and an Olfa knife (figure 6), is a clear analog for a digital modeling workflow of aggregating and manipulating generic solids and then assigning materials to them. This is a much more direct process of feedback between digital and physical models than 3D printing or CNC milling, which works best in an inflexible, post-"booleanunion" manner, in which the physical model can only be produced from a complete or fixed digital one, or then cutting and casting specific materials, which requires time and specialized equipment.

\section{MODELS}

The generative, rather than documentary, production of physical models is as important to the current state of things in architecture as computers are. The defining formal features of contemporary architecture are those learned from physical modeling techniques. Much of contemporary architecture is indebted to practices that attempted to literally translate the qualities of physical models into buildings. Think of immersive model photographs and endless stacks of foam and folded paper in OMA's monographs (figure 7), or Herzog \& DeMeuron's catalogues of material studies (figure 8), or delicate assemblies of thin sheets of white paper in SANAA's office (figure 9). Frank Gehry had to start using a computer, and then invented software, in order to build his paper and fabric models (figure 10). Reiser \& Umemoto is still modelling twisted surfaces from sheets of casting wax smuggled out of Cranbrook. ${ }^{3}$ The formal languages (stacks of blocks and other arrangements of geometrically simple forms, folded surfaces, the layering

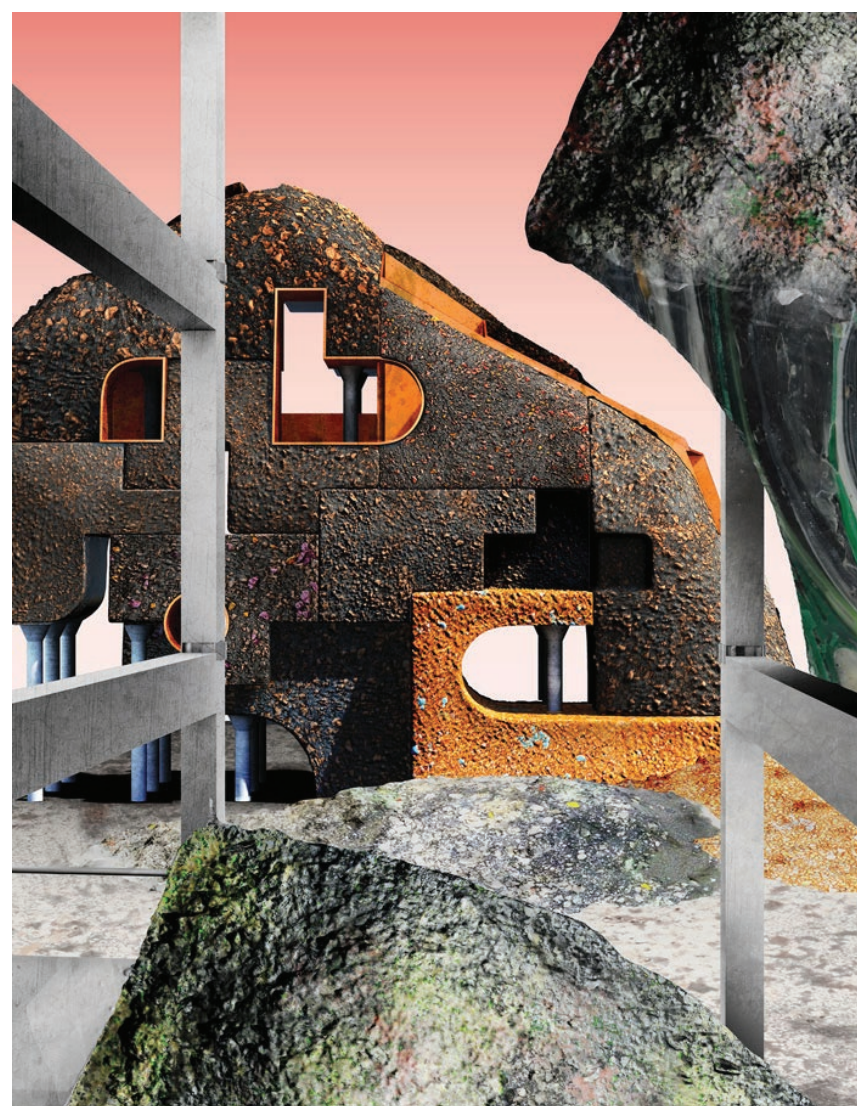

Figure 11. Detroit Reassembly Plan Model, $T+E+A+M$.

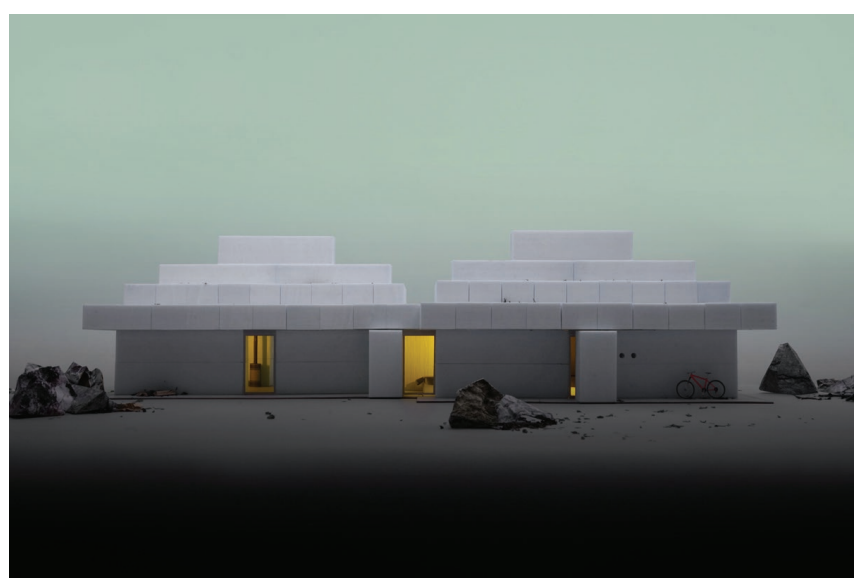

Figure 12. House 12 Model, MOS.

of veneers of material, the appearance of paper-thinness, supple drapery) that were developed in this period remain predominant, and architects, including those hosting this panel, today continue to attempt to conceive of and make digital models more like physical models, physical models more like digital models, and, should they be confronted with the opportunity, buildings more like both (figure 11). Today, even cruder and less superficially "digital" attitudes that use commonly available manual tools and 

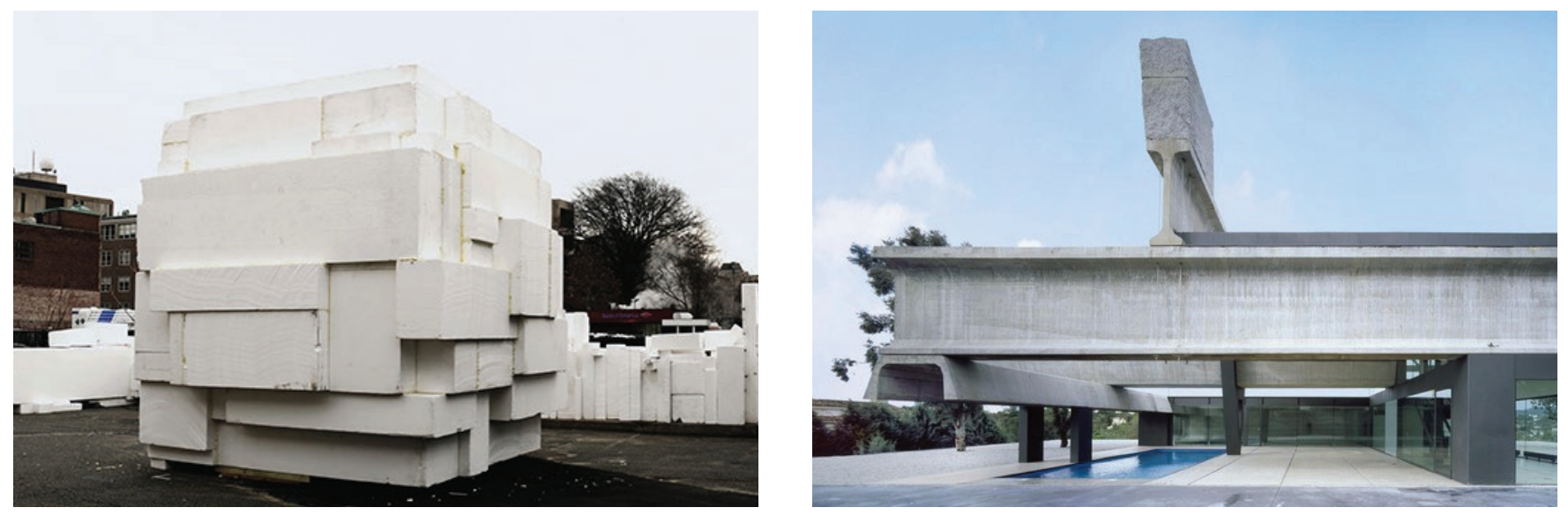

Figure 13. Cubic Igloo, Ensamble Studio.

Figure 14. Hemeroscopium House, Ensamble Studio.
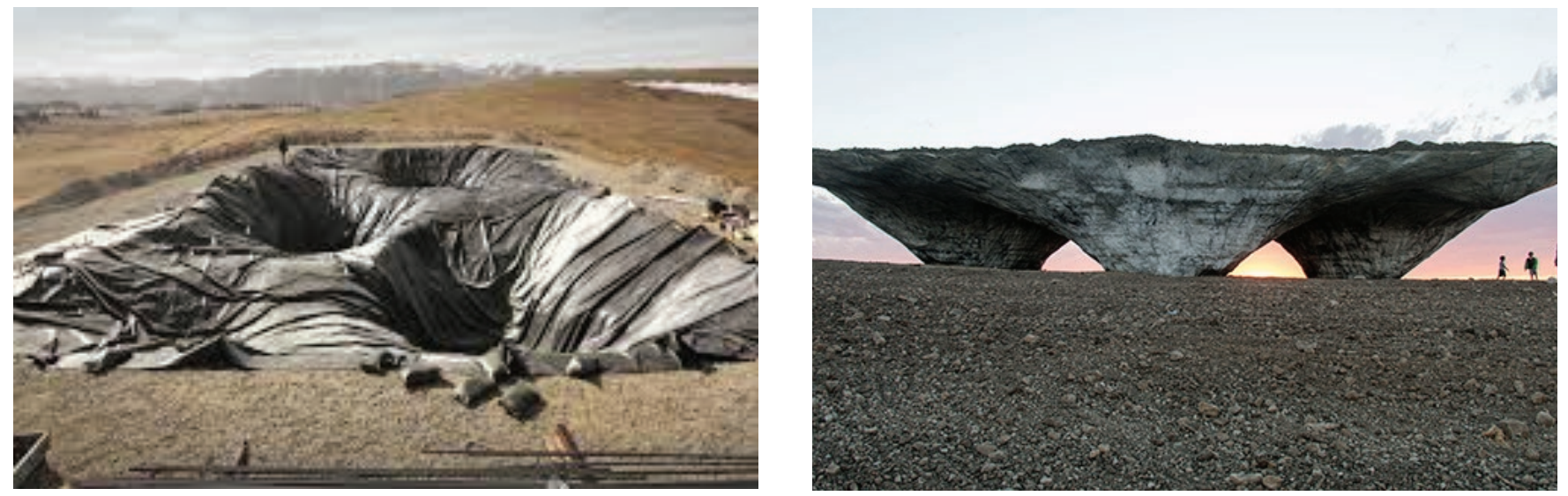

Figure 15. Tippet Rise Art Center, Ensamble Studio.

Figure 16. Tippet Rise Art Center, Ensamble Studio.
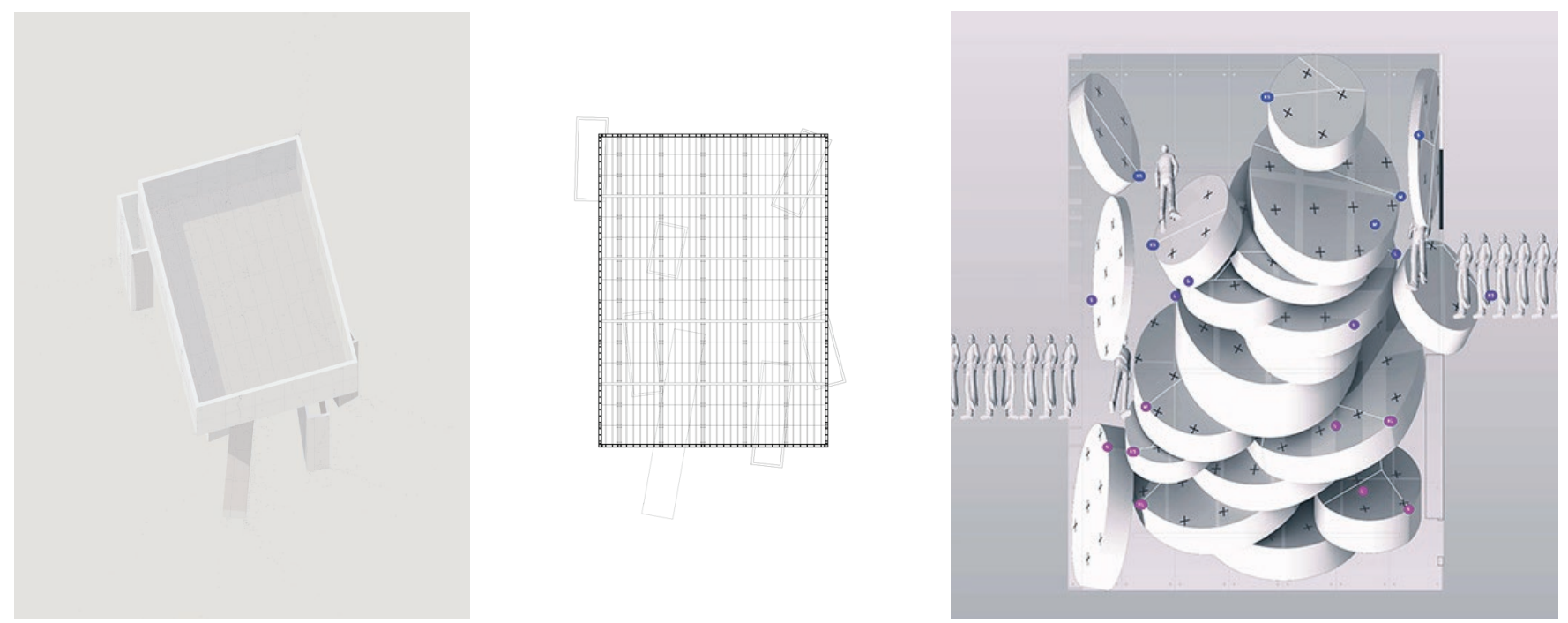

Figures 17-19. Left, PS1 Dolmen Oblique, First Office; center, PS1 Dolmen Plan, First Office; right, Training Wheels Plan Oblique, D.ESK (right). 
construction techniques predominate in this collapse of model and building: buildings made of stacked blocks of foam (figure 12), for instance, or ready-made pieces of highway infrastructure and rocks (figure 13), with modelmaking techniques of foam cutting or casting taken directly into the field (figures 14, 15, and 16).

The physical model has been the constant other to the digital in part because the defining characteristic of digital technology in architecture has not been complex geometry or photoreal rendering, but the structural division of model space from paper space. That is, since the advent of digital modeling software, most projects exist first, or primarily, as models, and then are translated to drawings, renderings, or what, following John May's recent arguments, should be today classified as digital images. ${ }^{4}$ One can produce a Palladian villa or Corbusian house without a model ${ }^{5}$--they are absolutely products of orthographic projection and drawing on flat surfaces. But one cannot produce the Guggenheim Bilbao or the Seattle Public Library without a model-the buildings exist fully in the logic of models-assemblies of discrete materials-rather than drawings-continuous lines projected orthographically into space. As the geometric fervor of the "high" digital subsides, physical models and digital models are increasingly converging, not because we can "print" physical models from digital machines, but because we've trained ourselves to build digital models as we would physical ones, one sheet or slab or block of material at time. If the digital inflects or undergirds our every interaction with the world, we also cannot understand the digital outside of our embodied experience of physical space and materials, and the myriad ways in which that understanding has been programmed into the model space of our digital tools. And because buildings are like very large models, some internalized understanding of the rules of the physical aggregation of things when using software that isn't pre-programmed with those physical rules makes sense. Architecture is in some sense always tending towards the construction of physical models, particularly when one starts with a model-digital or physical-rather than a drawing or an image.

\section{STANDARDS}

In our work, we regard the various softwares we use in a manner analogous to the way we might think of a 2 " $x 4$ " aluminum stud or a $1 / 2$ " mortar joint or a $4^{\prime} \times 8^{\prime}$ sheet of plywood: "extrude" or "booleandifference" or the dull grey sheen of the default viewport settings of the Rhino modeling interface are standards to work with and through. We find it more satisfying to develop a coherent approach from these standards than to break them. By working with them, perhaps we are working towards a common language with our peers and a capacity to directly and relatively easily translate models into buildings. It is not merely

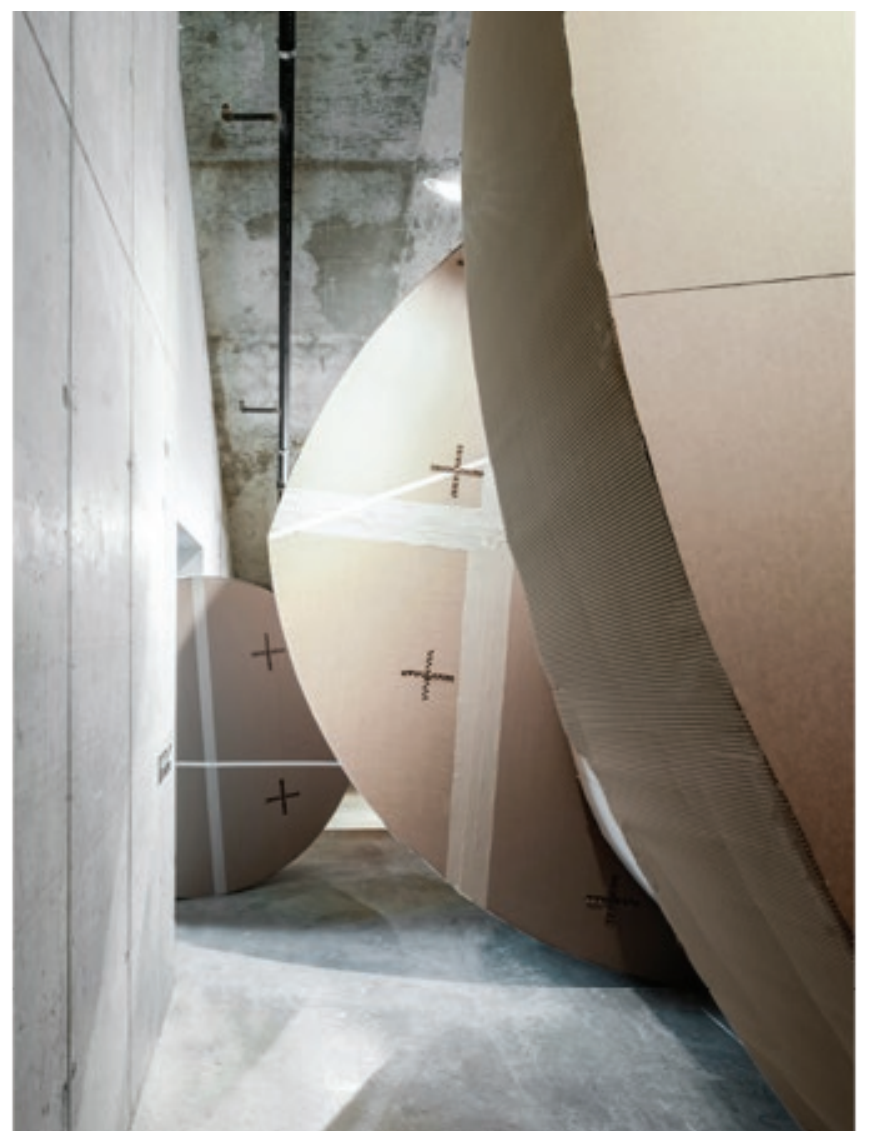

Figure 20. Training Wheels Installation, D.ESK

that the digital standards are analogous to constructional ones, as elaborated above; we, and others like us, have internalized the standards of physical construction in the construction of digital models, and vice-versa. Rather than translating digital surfaces into $4^{\prime} \times 8^{\prime}$ sheets or $2^{\prime \prime} \times 4^{\prime \prime}$ studs spaced $16^{\prime \prime}$ inches on center, these physical standards are built into the digital models themselves, and are therefore anticipated in the building, rather than applied as a post rationalization of immaterial digital forms.

This approach to modeling is not exceptional, it encompasses other things that are out there (figures 17-21). We might attribute this convergence between practices to the increasing proliferation of images and the impact of platforms like Instagram (though only one of us has an Instagram account) or to a particular set of institutional affiliations, but we might also speculate that this is a product of a generation for whom engagement with the "digital" was not an iconoclastic choice but an inevitability, whose sensibilities have been shaped less by an ambition to be weird or exceptional or novel and more by an interest in the ordinary or the typical or the known. We are all mining digital tools in an effort to reveal or establish something approaching standardization in their application. Rather than intricate and highly complex digital processes, these 


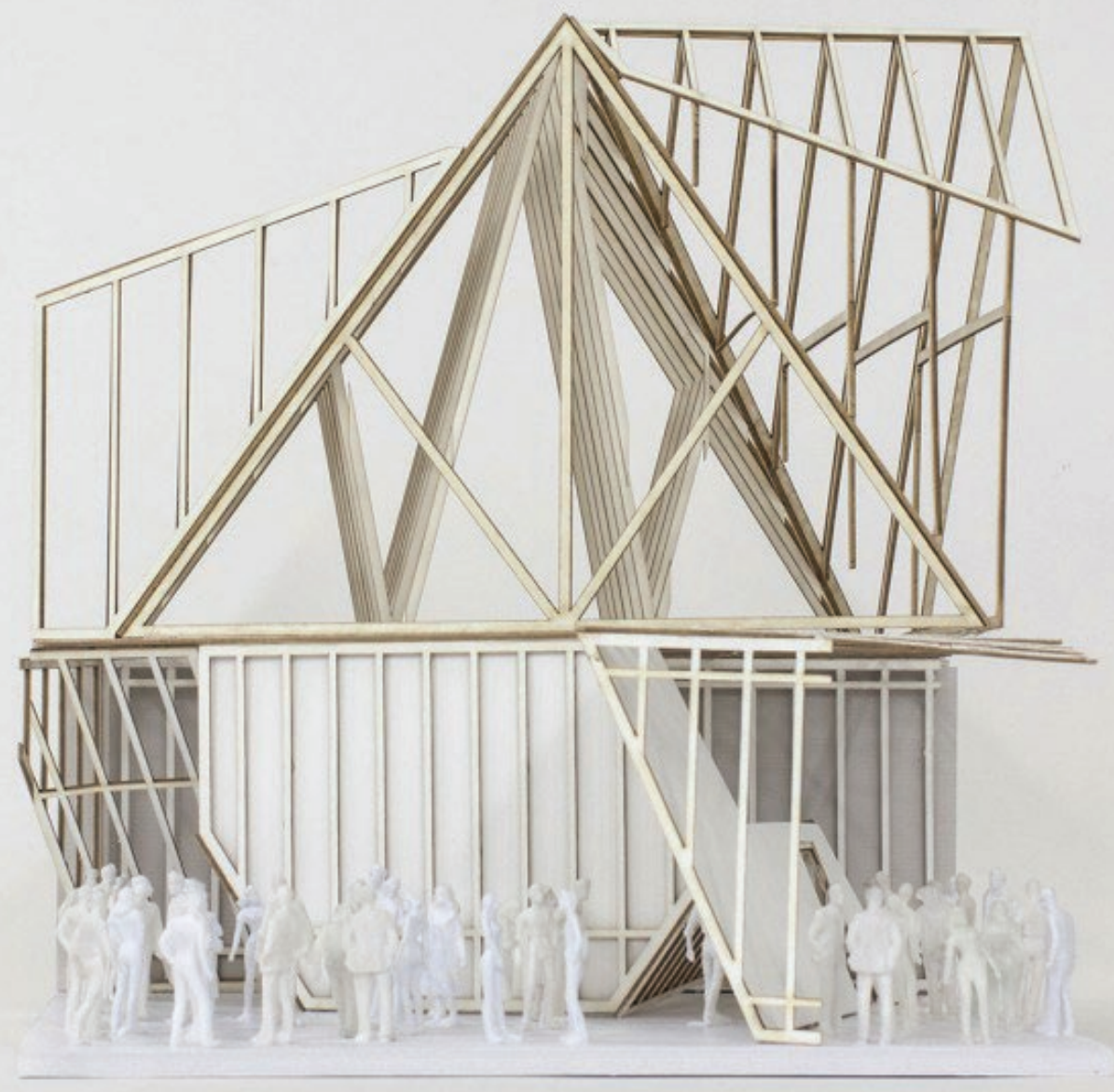

Figure 21. Roof Deck at PS1, Besler and Sons.

processes are straightforward--easy even--as they default to the most basic commands or options or settings within the most common software. Process is not obfuscated and to that extent no intellectual property rights are claimed; these are highly constrained and transparent techniques that are easily and intentionally reproducible.

\section{LITERAL}

If there is a word that encapsulates our generation, it is literally, the needless injected modifier, bane of pedants for its improper use and debasement of the English language. But perhaps this continual claim as to the reality and authenticity of things reflects a need to reassure ourselves that our technological mediated lives are not alienated, unreal or inauthentic. Rather than assuming a gulf between the virtual of the digital and the real of construction, we see both as material things, and deal with those materials as directly, or literally as we can, without prioritizing the material qualities of one or the other, and thereby deeming it the more "authentic" expression of the idea (figures 22-24).
As opposed to previous celebrations of the abstractions and translations that existed between drawings, models and buildings, where projects could be understood in each medium to be autonomous from one another, we try, as best as we can, to lose no information in the translation from image to model to building (figures 25-30). In that way, in whatever state the project exists, it is complete unto itself, contains all of the qualities that it would in any other state (to the best of our capacity to achieve that). In this way, rather than celebrating, with a masochistic undertone, the fact that drawings are categorically different than buildings, and are the exclusive purview of architecture, the site of its most radical ambitions, full of complexities and abstractions that could never be realized in built form, and therefore all those poorly executed built versions of drawings are excused, because the world doesn't understand (or doesn't matter), we think we can absolutely build everything we model, image everything we build, model everything we image, without any significant loss (figures 31-35). That constrains what we build or model or image, 


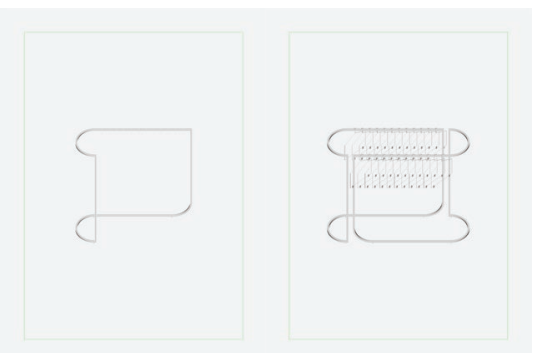

Figure 22. Clothing Racks for Solid and Striped, Medium Office.

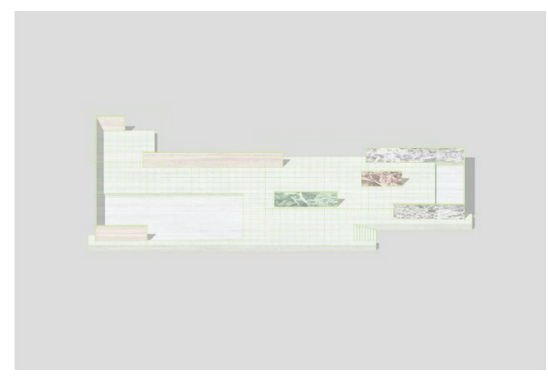

Figure 25. Pavillion 004, Medium Office.

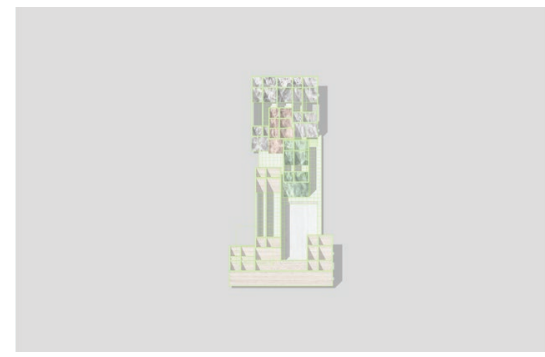

Figure 28. Pavillion 004, Medium Office.

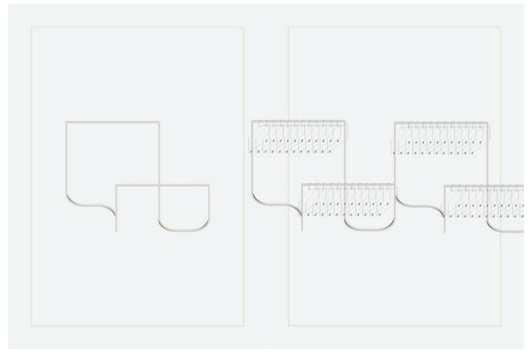

Figure 23. Clothing Racks for Solid and Striped, Medium Office.

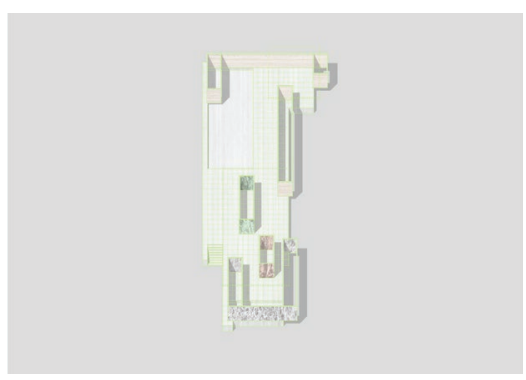

Figure 26. Pavillion 004, Medium Office.

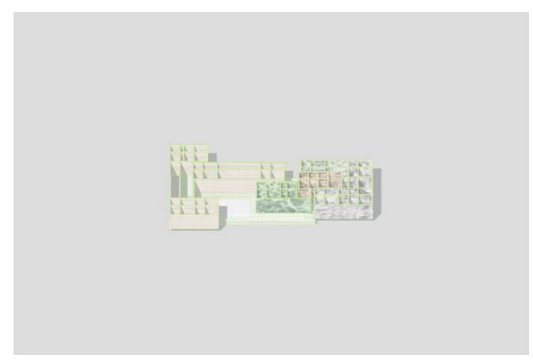

Figure 29. Pavillion 004, Medium Office.

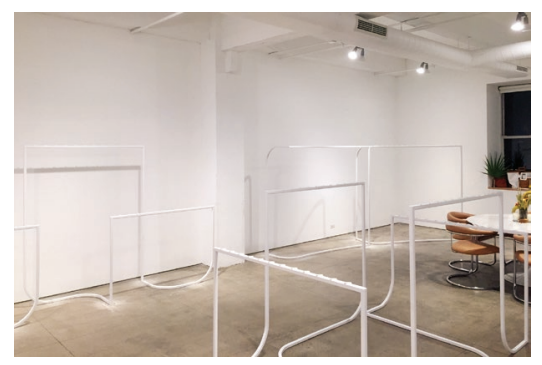

Figure 24. Clothing Racks for Solid and Striped, Medium Office.

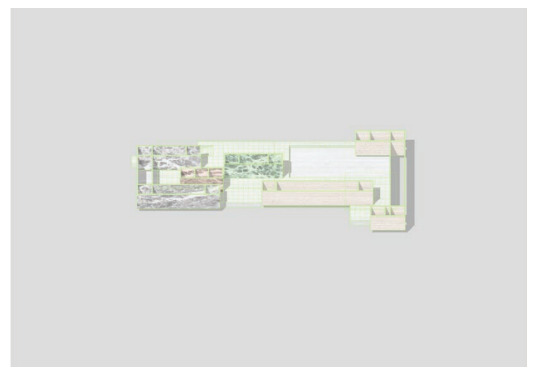

Figure 27. Pavillion 004, Medium Office.

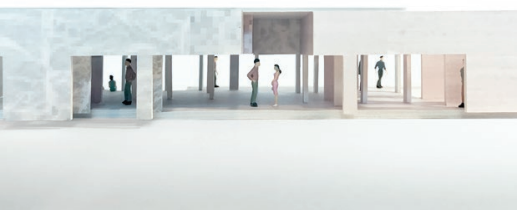

Figure 30. Pavillion 004, Medium Office. but those material constraints can perhaps be exploited productively rather than resisted futilely. What you see is what it is, a more or less direct expression of the way in which it is conceived and made, which is not exclusively digital or physical (figure 36). Perhaps this literalness, which voids architecture (or at least us) of some of its (or at least our) theoretical anxieties and hopefully some of its pretensions, also opens a space for those who engage with architecture-clients, contractors, users, audiencesto do so differently. Inverting Michael Fried's critique of literalness in art, but not his terms (which were, as Mark Linder has suggested, precisely a critique of arts increasingly architectural qualities), ${ }^{6}$ perhaps in architecture, literalness can foster a collective and productive form of openness and interaction, rather than a faith in the transcendent power of singular and ambiguous expressions. ${ }^{7}$

The relationship of contemporary to "literal" art is not accidental. Like those artists resisting the worship of abstract expressions elevated to the status of heroic existential struggle, the increasingly suspect divide between the mediums of painting and sculpture, or the unquestioning acceptance of the institutional frames of the museum and the gallery and the values they impose, we are ready to move beyond the "abstract expressionist" phase of late "digital" style, with its impossible geometries, self-mythologizing and slippery philosophical rhetoric, and uncritical acceptance of the need for great patrons, exploitative competitions, vast sums of capital, and all the computational power a team of unpaid interns can handle.

The philosophical movement of Object Oriented Ontology, particularly the writing of Graham Harmon, provided the last "digital" vanguard-centered around early students of the paperless studios of the Columbia GSAPP AAD program-with the terms for a theoretical framework for excess and alienation, supporting the idea that architecture can be more meaningful if it is ambiguous or beyond comprehension, always in some sense withdrawn from the subject that engages it. ${ }^{8}$ This conflated an ontological position with a set of more or less arbitrary aesthetic values, and re-enacted precisely the problematic translation of 


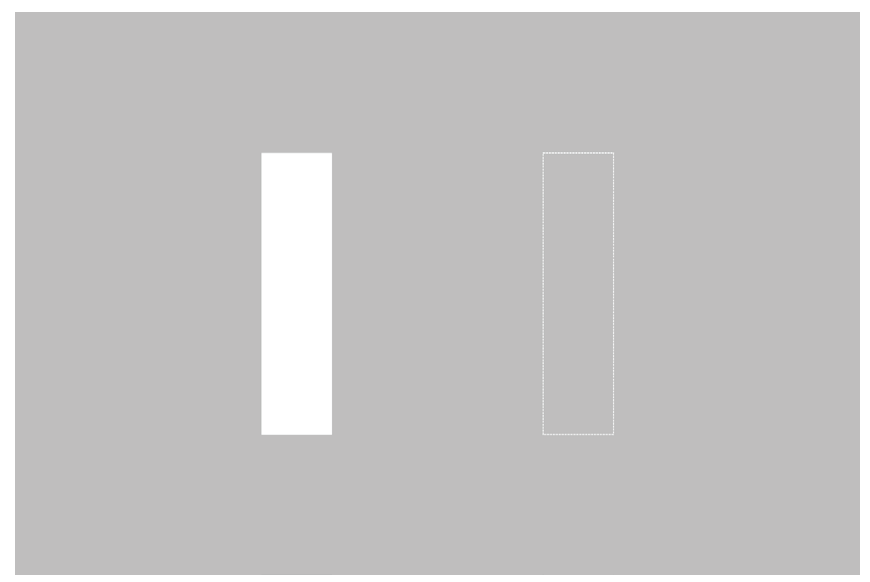

Figure 31. Urbanism 002, Medium Office.

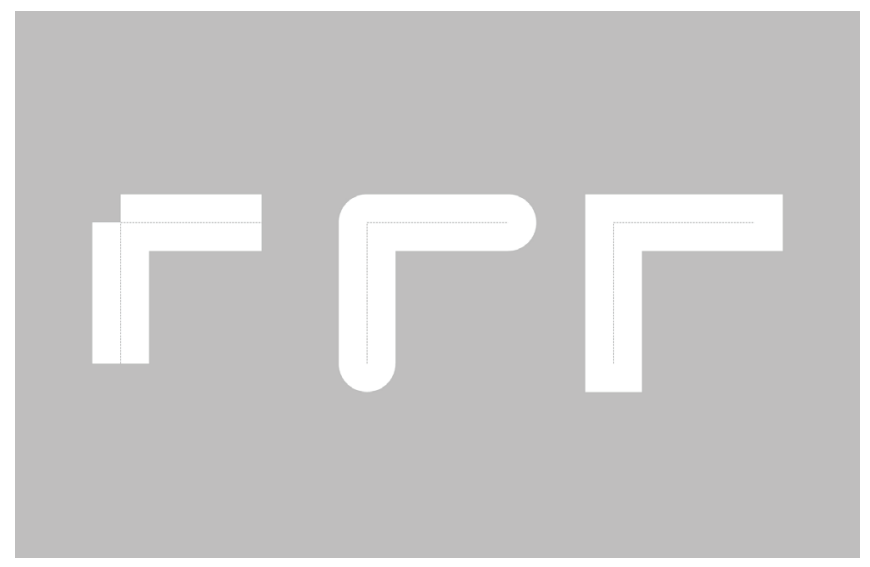

Figure 33. Urbanism 002, Medium Office.

philosophical metaphors and practices into architectural forms that these architects were seeking to overcome in their critique of architecture's absorption of poststructuralist theory. As a matter of ontology, architecture is always withdrawn, in the sense that it can never be instantaneously or wholly apprehended. It is not more withdrawn if it seems to recede at acute angles, is painted black, or is encrusted with many small objects. Perhaps a lack of overt formal ambition, ${ }^{9}$ and attendant theoretical elaboration, among a newer generation is in part an attempt to clarify what architecture-a material practice and a material object-is and can do.

For Banham, the black box problem came down to the way in which architecture is always, inevitably about sensibility towards work, which separates those things that have emerged from a more or less continuous tradition of inherited techniques beginning with fifteenth-century Florentine disegno from those things produced by NASA engineers or vernacular builders. ${ }^{10}$ To be an architect means to pay as much attention to how you are doing something as to what you do, to create a discourse around tools and working methods, and to make those central to the conception and production of your work. In this respect

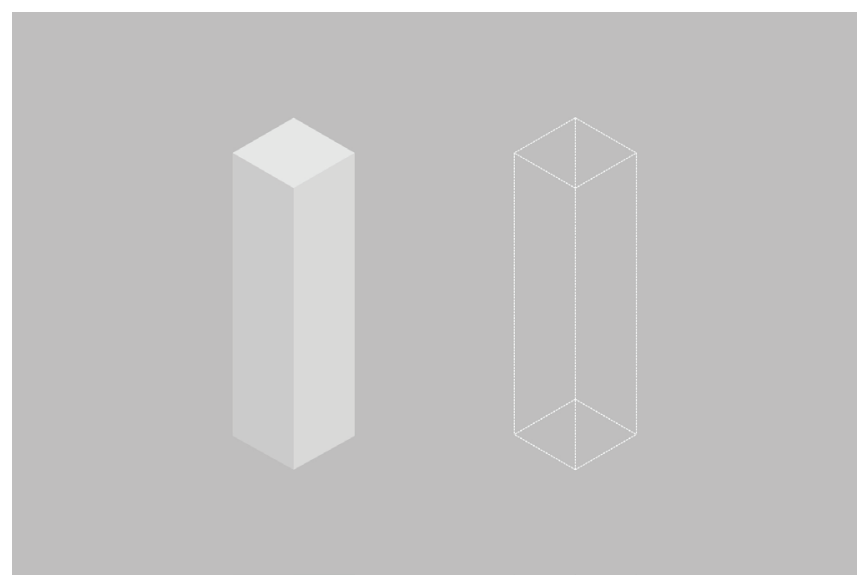

Figure 32. Urbanism 002, Medium Office.

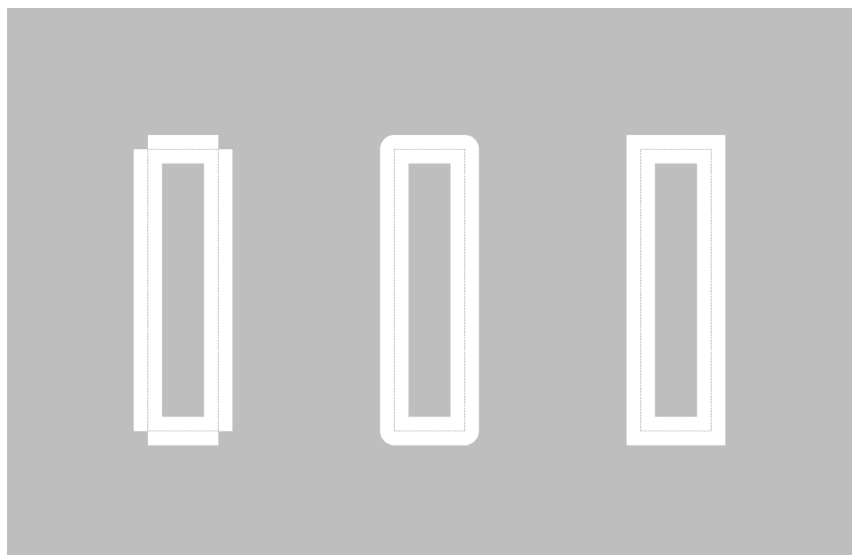

Figure 34. Urbanism 002, Medium Office.

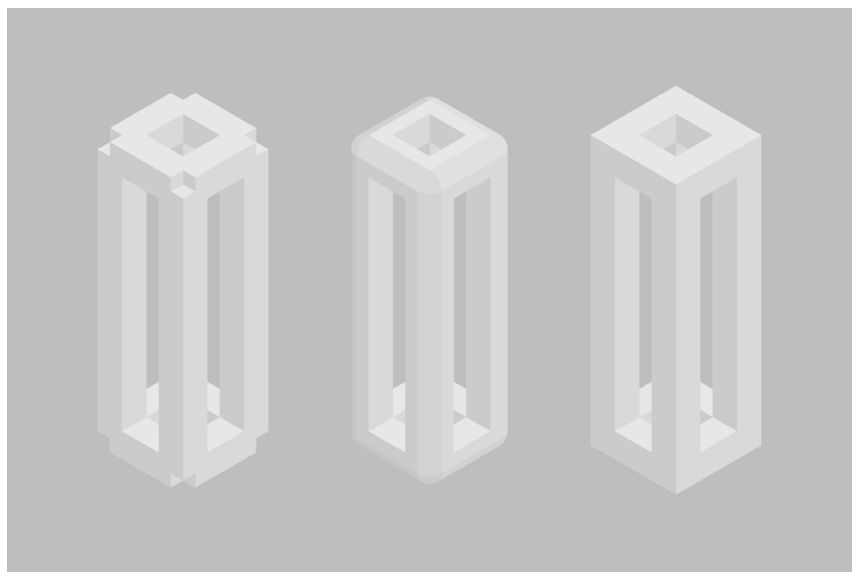

Figure 35. Urbanism 002, Medium Office.

there is no threat in opening the black box, what will be found inside is not a theoretical house of cards or a flawless functional reasoning, but a particular set of historically and materially specific tools with which architects produce architecture, and which inevitably condition those things that they produce. Our buildings work, and they can be, as they are here perhaps, theorized in specific disciplinary 
language, but what they are at their core is the product of the tools available to us as a given moment, which we attempt to use as directly as possible, while reflecting on why and how we do so. In this, we aim towards a more open, collective and accessible practice, which finds opportunities, rather than limitations, in the conventional tools and material constraints with which architects work.

\section{ENDNOTES}

1 For more on these distinctions, see Matthew Allen, "Computational Labor, Computational Aesthetics," Project 7 (Summer 2018).

2 A term popularized by Marc Pensky, "Digital Immigrants, Digital Natives," On the Horizon 9, no. 5 (October 2001).

3 "Conversation with Jesse Reiser," Project 2 (Summer 2013).

4 John May, "Everything is Already an Image," Log 40 (Spring/Summer 2017).

5 As architecture becomes less articulated and individuated in its details and construction (e.g. from carved stones to industrially-produced panels to full-scale $3 \mathrm{D}$ printing), the capacity of physical models (and digital models) to comprehensively anticipate the qualities of building increases. This was accelerated by the formal articulation of distinct and geometrically simple parts, treated monolithically by single materials, in the work of Mies van der Rohe, which remains a touchstone throughout the discipline for the ease with which its constructional logic translates to the aggregation of geometrically simple discrete and "texturemapped" forms in digital and physical models.

6 Mark Linder, Nothing Less than Literal: Architecture after Minimalism (Cambridge, MA: The MIT Press, 2004).

7 Michael Fried, "Art and Objecthood," Artforum 5, no. 10 (Summer 1967).

8 While this reflects any number of essays by Mark Foster Gage, David Ruy, Tom Wiscombe and others (see, for instance, Wiscombe, "Disceteness, or Towards a Flat Ontology of Architecture," Project 3 (Spring 2014)), it reflects also first-hand experience of a pedagogical context at SCl-Arc in the years 2014-17, where Wiscombe and later Ruy and Harmon taught.

9 If ambition is taken in considered evaluated in recent terms of formalism, which has tended to conflate complicated philosophical metaphors and practices and complicated built forms (a different kind of literalness, that deconstruction involves lots of broken up parts, rhizomes should be shaped like rhizomes, and sacks of rocks like sacks of rocks).

10 Reyner Banham, "A Black Box: The Secret Profession of Architecture," New Statesman and Society (October 12, 1990).

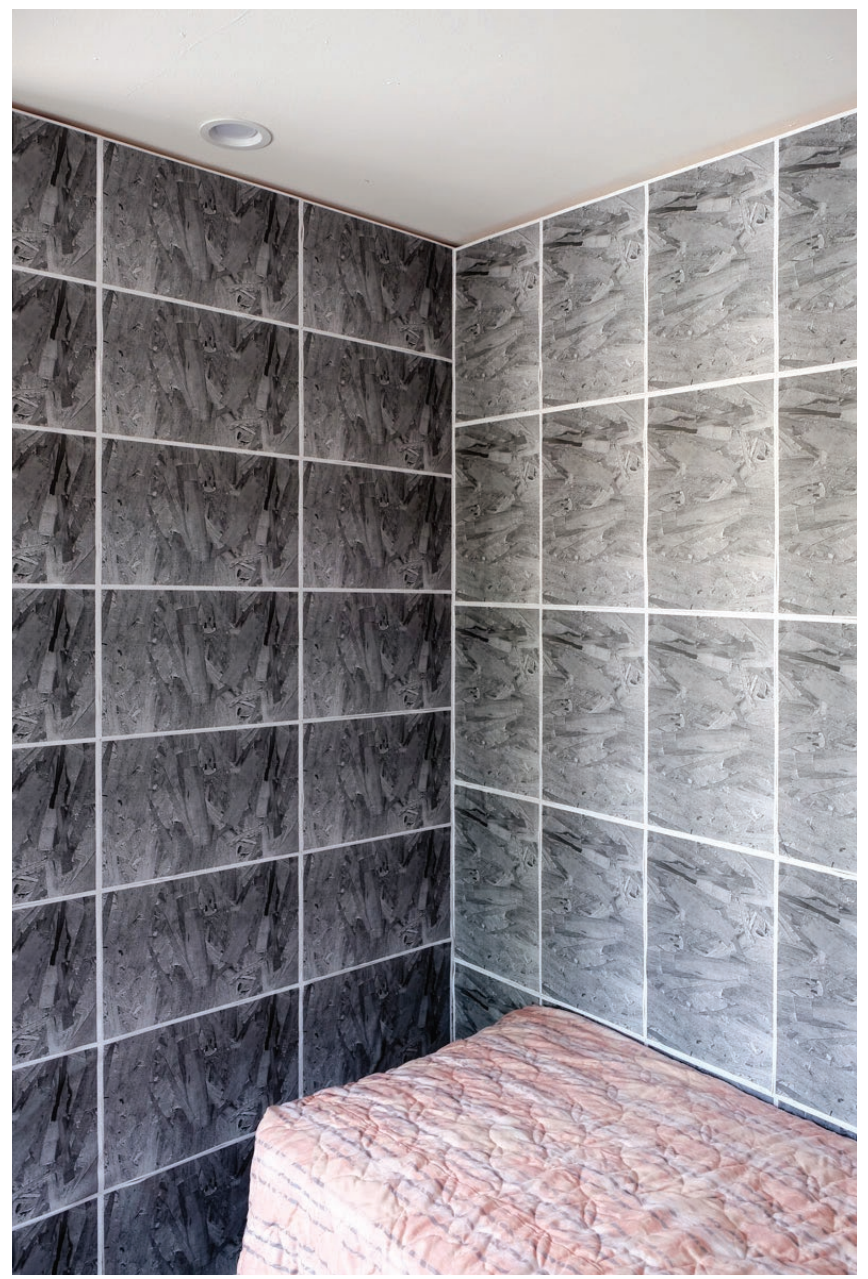

Figure 36. One Night Stand LA, Medium Office. 